\title{
CRISPR Plants: A Course Based Undergraduate Research Experience
}

\section{Dawn Carter}

\author{
School of Life Sciences, Rochester Institute of Technology, 85 Lomb Memorial Dr, Gosnell Hall, \\ Rochester NY 14623 USA \\ (dxcsse@rit.edu)
}

\begin{abstract}
With the rapid advances in gene editing using CRISPR/Cas 9 and associated technologies, undergraduate students are seeking opportunities to learn about and experience this exciting technology. Plant Molecular Biology is a laboratory based upper level elective course at RIT. We describe the development of a course-based undergraduate research experience (CURE) to explore CRISPR/Cas 9 editing in Arabidopsis thaliana. Groups of students selected gene targets, designed guide RNAs, produced plasmids containing the guide RNAs, and introduced the plasmids into Arabidopsis thaliana using Agrobacterium tumefaciens-mediated floral dip transformation. In addition, we performed in vitro assays to determine the ability of our guide RNA sequences to target and cleave template DNA in the presence of Cas 9. Students used a variety of online tools in the project design and designed their own timelines to achieving their goals. We discuss preliminary results as well as further work required to achieve this workflow in a single 14-week semester.
\end{abstract}

Keywords: CRISPR/Cas 9, CURE, Arabidopsis thaliana, Agrobacterium tumefaciens, undergraduate research

Link to Original Poster File: https://doi.org/10.37590/able.v41.poster60

\section{Mission, Review Process \& Disclaimer}

The Association for Biology Laboratory Education (ABLE) was founded in 1979 to promote information exchange among university and college educators actively concerned with teaching biology in a laboratory setting. The focus of ABLE is to improve the undergraduate biology laboratory experience by promoting the development and dissemination of interesting, innovative, and reliable laboratory exercises. For more information about ABLE, please visit http://www.ableweb.org/.

Advances in Biology Laboratory Education is the peer-reviewed publication of the conference of the Association for Biology Laboratory Education. Published articles and extended abstracts are evaluated and selected by a committee prior to presentation at the conference, peer-reviewed by participants at the conference, and edited by members of the ABLE Editorial Board. Published abstracts are evaluated and selected by a committee prior to presentation at the conference.

\section{Citing This Article}

Carter D. 2020. CRISPR plants: a course based undergraduate research experience. Article 60 In: McMahon K, editor. Advances in biology laboratory education. Volume 41. Publication of the 41st Conference of the Association for Biology Laboratory Education (ABLE). https://doi.org/10.37590/able.v41.abs60

Compilation (C) 2020 by the Association for Biology Laboratory Education, ISBN 1-890444-17-0. All rights reserved. No part of this publication may be reproduced, stored in a retrieval system, or transmitted, in any form or by any means, electronic, mechanical, photocopying, recording, or otherwise, without the prior written permission of the copyright owner.

ABLE strongly encourages individuals to use the exercises in this volume in their teaching program. If this exercise is used solely at one's own institution with no intent for profit, it is excluded from the preceding copyright restriction, unless otherwise noted on the copyright notice of the individual chapter in this volume. Proper credit to this publication must be included in your laboratory outline for each use; a sample citation is given above. 